\title{
Research on the Construction of Education System of Innovation and Entrepreneurship Based on Practice Teaching in Undergraduate Colleges
}

\author{
Guang Han \\ Jilin Agricultural University, Changchun, 130118, China
}

Keywords: Innovation and entrepreneurship, Practice teaching, Undergraduate colleges.

\begin{abstract}
Innovation and entrepreneurship education is a systematic education which aims to cultivate awareness, spirit, knowledge and ability of the innovation and entrepreneurship. Practice teaching plays a key role in the construction of innovation and entrepreneurship education system in colleges and universities. This paper analyzes the construction model of innovation and entrepreneurship education system based on subject contest, project cultivation and entrepreneurship practice and points out the safeguard measures of constructing the education system of innovation and entrepreneurship to provide some references for the relevant researchers.
\end{abstract}

\section{Introduction}

The cultivation of the innovation and entrepreneurship ability of contemporary college students have become an urgent problem in higher education field, which is one of the core competitiveness of colleges and universities. It is the core of higher education development strategy. The practice teaching system is an organic whole, and most scholars think it has narrow and broad connotation. In general, the target, content, management, evaluation system and other factors constitute the whole practical teaching system which is in accordance with the general level to describe the gas and practical teaching system in narrow sense it refers to the content system of practical teaching. This article is based on the connotation of the generalized practice teaching system, but it is not limited to the four elements of its goal, content, management and evaluation. The practical teaching system is an organic whole which is based on the training target of practical teaching talents as the core, the practical teaching activities as the main content, and the corresponding environmental resources as supporting conditions. The core of students' innovative ability is innovation, which is sublimated based on a certain degree of innovation. Practical ability is the cornerstone of the development of innovative ability, and the construction of practical teaching system for innovation and entrepreneurship training in universities is in line with the requirements of modern education and social talents. Practice teaching is the foundation of cultivating students' creative ability. The stimulation of students' entrepreneurial potential is inseparable from the accumulation of innovative ability, and the accumulation of innovative ability cannot be separated from the promotion of practical ability. Without practical ability, innovation ability cannot be developed. Students in practice continue to accumulate their practical ability, and form a good sense of innovation, virtually will make their own innovative ability gradually improved. Only through the practice teaching system can we realize the function of practice teaching more systematically. It is a necessary condition for the development of students' ability. Therefore, to keep up with the pace of the transformation of the university education and to meet the requirements of the new situation, it is urgent to explore the innovation and entrepreneurship educational system based on practical teaching of the undergraduate colleges. 


\section{Educational System of Innovation and Entrepreneurship Based on Practice Teaching}

Subject Contest. Although the contents and forms of different subject contest are different, they can be divided into three types, namely, quality enhancement, professional strengthening and innovation and entrepreneurial ability expansion. To enhance the basic quality of college students is essential for any subject, any professional training; the main purpose of professional strengthening is to improve the type of subject contest professional students' comprehensive ability; innovative academic competition focuses on the process of knowledge innovation by students accumulated over the years, is to cultivate students' divergent thinking and creative. The role of several kinds of competitions in teaching is obvious, and the basic aim is to promote the cultivation of creative talents. The latter two kinds of competitions have more prominent influence on practical teaching. Subject contest itself is not an end, and its real function is to deepen the students' grasp of basic theoretical knowledge and the understanding of the mechanism behind the professional practice engineering. The aim is to develop and improve the students especially the top students of the science and technology innovation ability, through the organization of seminars, training, seminars, competitions and other activities of science and technology innovation, cultivating students' science and technology elite. The technological innovation activities center for university students based on the established program design association of eight relatively strong professional students' innovation organization, propaganda and organization dedicated to the extracurricular science and technology activities, serve the students to participate in various disciplines and professional competitions at all levels: after years of exploration and reform, innovation of science and technology has built student activity center has made great progress in the organization of financial security, management system, practice conditions, teachers, incentive mechanism, teaching concept and reform, cultivating students' innovation ability, external training and technology service. At the same time, the college should introduce the management system of professional competition platform, such as teacher's workload recognition, and lay a good foundation for the development of subject contest.

Project Cultivation. The implementation of the project is the best way to reflect the research process. In the process of implementation of the project, whether it is to complete the plan and design of project feasibility study report writing, communication and reporting results, students encounter problems not only from the professional knowledge, will encounter theory knowledge and social practice is not the same confusion. Therefore, in the implementation of the project, we should not blindly pursue the results of the project, but should pay attention to the process of research. In the process, students take the initiative to learn, learn to team work, learn to understand failure, learn how to transform, and learn to serve society. It is also the essence of project research. Although it has made remarkable achievements in the competition, related work has been on the right track, but once the trouble is that the general competition ended, the students also contest works or achievements on the shelf, and with the student's graduation. This project is a good starting point, through the exploration of students' scientific research project reporting, project, mid-term examination, approval, reporting and other aspects of intellectual property rights to achieve competition achievements management, project reporting stage to take publicity guidance to the class as a unit, each class does not limit the declaration, and to encourage teachers to participate in the guidance, and then from the each class recommended innovation and entrepreneurship training projects through the review of the project, and give some financial support, the final merit recommended to the college. The college will further review the declaration and recommend it the province, the national college students' innovative entrepreneurship training project.

Entrepreneurship Practice. In recent years, the entrepreneurship problem of the college students has got more and more attention. Another fact is the employment difficulty of university students. One important reason is that university students have no personality, characteristics, employment competition ability, so many students in recent years, especially the science and engineering students to achieve employment through entrepreneurship. At the same time, the state has also launched a series of entrepreneurial support policies, such as youth entrepreneurship, leading programs, public support funds, small and medium-sized enterprises to support funds. College Students' innovative 
spirit and entrepreneurial desire more strongly the number of entrepreneurs to make a demonstration, leading the typical talent shows itself, another batch of talented students have dreams, abandon the traditional concept of employment, to join the army of entrepreneurship. Students majoring in science and engineering have a natural and professional advantage. They must be inclined to high-tech and high-tech fields from the very beginning. These fields tend to have low threshold and great potential for development. Some venture capitalists are also happy to finance their business plans. Entrepreneurship financing is one of the most important concerns of entrepreneurial students. The poor financing channel is an important factor that restricts the university students' entrepreneurial activities. For college students, the more funds they have, the greater the choice, and the more opportunities for success. In addition to the good quality of students, it is necessary to build a financing credit support system to meet the needs of enterprise growth and development. Building financial credit support system requires the integration of financial resources and factors to help college students raise their start-up funds.

\section{Safeguard Countermeasures of Educational System of Innovation and Entrepreneurship Based on Practice Teaching}

Strengthen Organization Guarantees. To strengthen the practice management of innovation and entrepreneurship, it is necessary to set up a corresponding organizational system, and colleges and universities should ensure the implementation of management. The daily management of practice teaching innovation and entrepreneurship can build schools, two levels of practice teaching steering committee, the implementation of the daily teaching activities carried out supervision and inspection; evaluation results and incentives for innovation and entrepreneurship should establish the school department two levels of innovation and entrepreneurial achievements appraisal committee, the completion of the achievement level and achievement awards identification issues identified. Through the above construction organization, to provide effective supervision and positive incentives for innovation and entrepreneurship practice teaching to ensure the innovation practice teaching standardized management at the same time, and constantly improve the teaching effect and quality of entrepreneurship. Different practice teaching platforms should be designed according to different stages and different levels of practice teaching. The course experiment platform is mainly engaged in the course experiment of entrepreneurial cognition and entrepreneurial quality training. It is necessary to establish a curriculum laboratory, equipped with an entrepreneurial quality testing system software. Mainly through the implementation of entrepreneurial quality test, career planning, entrepreneurship, quality development training and other experimental projects to implement teaching. Among them, the entrepreneurial quality test is completed through the computer software system test, and the training of entrepreneurial quality development is carried out through practical teaching, teacher organizations, training games and projects in the curriculum laboratory. Innovation and entrepreneurship base mainly carries out the actual operation of innovative enterprises, and is the incubator of start-ups. In the base, we will apply the results of the enterprise simulation training stage to real operation enterprises and create economic value. On this basis, we promote the establishment of new projects related enterprises, attract more students into entrepreneurship practice, and truly realize the overall improvement of students' entrepreneurial ability.

Cultivate Teacher Team. The construction of teaching staff is the foundation of innovative talents training. Practical teaching not only needs solid theory knowledge, but also needs skillful operation skill and rich engineering practice experience. Therefore, the experimental center should focus on the cultivation of innovative teachers, adhere to the combination of external introduction and internal training, and build a team of teachers. The level of teachers' professional skills in our daily teaching and research, teachers are relatively solid theoretical foundation, wide knowledge, strong ability and experimental teaching and engineering practice experience, create professional teachers and practice teachers exchange platform, teachers organize the exchange of learning, absorbing new experimental center, training exercise, i.e. with a wealth of theoretical knowledge and strong practical ability of the teacher team. The rich practical experience pays more attention to the skillful operation 
of each stage of the enterprise. Therefore, it is difficult to meet the requirements of the practical teaching objectives of innovation and entrepreneurship for the long time engaged in theoretical teaching, mainly in universities, and lack of practical experience. In view of this, security system of teaching innovation and entrepreneurship practice consists of two parts: one is the college teachers in colleges and universities with entrepreneurship education practice and practical experience. The other is the practice teaching from the industry guidance teachers. The practice of independent entrepreneurship requires external practice teaching, and the guiding teacher plays a leading role. The college guidance teacher can play the role of auxiliary management, while carrying out the accumulation of their own practical experience. Therefore, teachers safeguard system requires the establishment of external incentive mechanism management practice guidance teachers, to ensure that teachers regulate and effectively carry out practical teaching work and the teaching objective realization of innovation and entrepreneurship teaching.

Establish Special Funds. Capital is the primary resource of the innovation and entrepreneurship education. The practice of student entrepreneurship funds is mainly set up by the government and private entrepreneurs to set up venture fund investment risk fund and the school set up the venture fund, but most capital venture funds are very limited. Perfect the construction of entrepreneurial practice platform for students, focus on supporting the construction of innovative curriculum system, and strengthen the guidance of teachers, innovation and entrepreneurship training program of capital investment, and gradually form college students' innovation and entrepreneurship practice platform has the characteristics of integration. The construction of innovation and entrepreneurship practice teaching platform needs a large amount of capital to purchase equipment, equip experimental sites, enter the stage of self-establishment enterprises, and more need to start capital investment and carry out actual operation. Therefore, the effective operation of the innovative practice teaching system depends on whether there is sufficient financial support. In addition, to arouse the enthusiasm of teachers and students to participate in the practice of innovation and entrepreneurship, it is necessary to establish incentive system, and need to invest funds. And every link of the practice teaching management of innovation and entrepreneurship also needs the necessary capital input. Therefore, we should set up a special fund for innovation and entrepreneurship, funded students to carry out scientific research and innovation activities and business plan, support and organize students to participate in the innovation of science and technology of the competition, in recognition of outstanding performance in the students' scientific activities of individual and collective, reward outstanding students and academic achievements and outstanding teachers work. At the same time, for the development of promising application of scientific and technological achievements of the transfer and development, conditional establishment of enterprises to provide financial support. To ensure the scientific use of funds, the fund guarantee system should include the special funds allocation system, special funds management measures and the efficiency evaluation of the funds.

\section{Conclusion}

The cultivation of college students' innovation and entrepreneurship ability is the real demand of establishing an innovative country and the need of economic and social development. Based on practice teaching, the innovation and entrepreneurship educational system of undergraduate colleges and universities is established, which enables students to sum up experience, draw lessons and enrich their knowledge and ability in the process of participating in practical teaching. Practice has proved that the subject contest, project cultivation and entrepreneurship practice can effectively enhance students' practical ability and innovative thinking, and lay a solid foundation for the future self-employment. 


\section{Acknowledgments}

This research is the results of the Scientific Research Subject of Higher Education of Jilin Provincial Association of Higher Education in 2016 (Grant No. JGJX2016D35).

\section{References}

[1] Xie Ruijie. Research on the practice teaching system as the goal of innovation and entrepreneurship ability cultivation [J]. Laboratory Science, 2016, 19(1): 174-177.

[2] Deng Langni, Huang Jingyi, Zhao Jun, Zhong Zhuanglin, Yang Donghui. Teaching Reform and Practice of Innovation and Entrepreneurship in Local Comprehensive University [J]. Sci-tech Innovation and Productivity, 2017(1): 47-49.

[3] Peng Xiaofeng, Cao Yang. Optimizing Practice Teaching System for the Cultivation of Engineering Innovation Entrepreneurship Capability [J]. Computer Knowledge and Technology, 2016, 12(10): 145-147.

[4] Hua Jucui. Construction and Practice of Practical Teaching System in Local Universities from the Perspective of Innovation and Entrepreneurship [J]. Modern Education Management, 2017(4): 92-96. 